\title{
Research improvement of the strength characteristics of rocks under volumetric compression
}

\author{
Eugeny Pudov ${ }^{1}$, Nikolay Bedarev ${ }^{1}$, Vitaly Shakhmanov ${ }^{1}$, and Oleg Lyubimov ${ }^{1,2 *}$ \\ ${ }^{1}$ T.F. Gorbachev Kuzbass State Technical University, branch in Prokopyevsk, 653039, 19a \\ Nogradskaya St., Prokopyevsk, Russian Federation \\ ${ }^{2}$ T.F. Gorbachev Kuzbass State Technical University, 650000, 28 Vesennyaya St., Kemerovo, \\ Russian Federation
}

\begin{abstract}
The article describes some aspects of the research and applied works, which the authors carried out to expand the scope of application in the study of rock strength indicators in the laboratory of KuzSTU (Prokopyevsk branch) on a complex equipment. It consists of an extreme deformation chamber and a volumetric compression chamber. It describes the disadvantages of the volumetric compression chamber. The disadvantages have been eliminated by using a special device for fixing the sample when descending into the volumetric compression chamber. The article also gives the description of the operation of a volumetric compression chamber with the possibility of testing rock samples for a breakage under the volumetric compression. The first test results are presented.
\end{abstract}

\section{Introduction}

The paper [1] outlines the need to expand the strength indicators of rocks. It is necessary since at present, there is a need for active use of such indicators as adhesion $\mathrm{C}$ and the angle of internal friction $\varphi$ in addition to the characteristics of uniaxial tension of the compression. For these purposes, at KuzSTU (a branch in Prokopyevsk) the authors actively use the Azimuth 85 D01 volumetric compression chamber, and in combination with the BV-21 an excessive deformation chamber. It becomes possible to obtain data to substantiate the stability of mineshafts by the indicators of ultimate strength $\left(\sigma_{\text {com.u }}\right)$. The indicators of long-term strength $\left(\sigma_{\text {com. }}\right)$ can show the pressure on the support of capital workings. It is also possible to predict how rocks are inclined to rock impacts by the pre-limit and excessive characteristics of rocks [2,3]. The article is devoted to some aspects of the research and applied works carried out by the authors.

\section{Theory}

Foreign authors [4 - 6] describe modeling taking into account the simulation of strength characteristics similar to specific field conditions. In addition, foreign authors [7 - 9] took into account the new characteristics of rocks in relation to local natural conditions. They studied the length

${ }^{*}$ Corresponding author: oleglyub@gmail.com 
of the reference pressure zones, and in works $[10,11]$ studied the amount of lowering of the roof in conveyor and ventilation drifts. They noted in works $[12,13]$ the complexity of solving the problem of effective and safe mining of reserves. They did not take into account most of the indicators of new characteristics of rocks in relation to specific mining-geological and mining-technical factors in this direction.

On the basis of tests of samples in the chamber without deformation, complete diagrams of the rocks deformation in the pre-limit and beyond state are constructed (modulus of elasticity E, modulus of decline M, long-term strength $\sigma_{\text {com.l }}$, residual strength $\sigma_{\text {com.r. }}$, etc.) in [12].

It is possible to predict the propensity of rocks for the mountain impacts by the ratio $\mathrm{M} / \mathrm{E}=\lambda$, with $\lambda>1$, based on the diagrams. Rocks are dangerous for the mountain impact.

According to the data of the work [12], a passport of the volumetric strength of coal combined with a passport of strength under uniaxial compression. It is made and presented in Fig.1. It is based on the data of Table 1 (the primary results are taken, Taldinskaya-Zapadnaya mine).

The work [12] on the basis of samples tests in the chamber without deformation presents complete diagrams of the rocks deformation in the pre-limit and beyond state (modulus of elasticity E, modulus of decline $\mathrm{M}$, long-term strength $\sigma \mathrm{cj}$. dl. residual strength $\sigma$ cj.ost, etc.).

Based on these diagrams, it is possible to predict that the rocks have a tendency for the mountain impacts by the ratio $\mathrm{M} / \mathrm{E}=\lambda$, with $\lambda>1$. Rocks are dangerous for mountain impacts. The passport of the volumetric strength of coal, combined with a passport of strength under uniaxial compression, was made and presented in Fig.1 on the basis of the data in Table 1 (the primary results are taken, the Taldinskaya-Zapadnaya mine) according to the data [9].

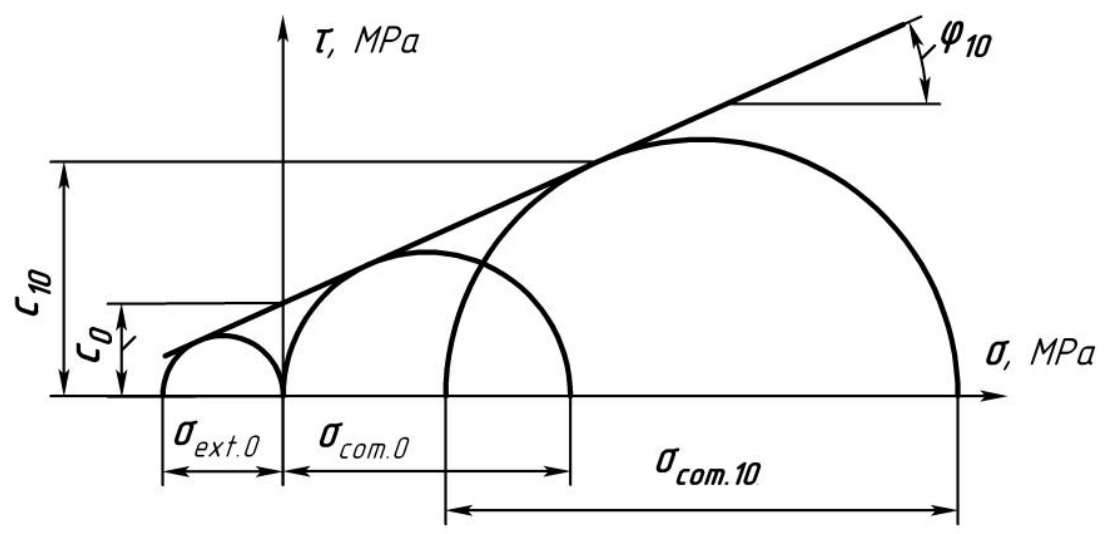

Fig. 1. Volume strength specification for coal: $\mathrm{C}_{0}=0.9 \mathrm{MPa} ; \mathrm{C}_{\text {cr }}=2.9 \mathrm{MPa} \sigma$ ext.o $=1.5 \mathrm{MPa} \quad \sigma$ com.o $=$ 3. $4 \mathrm{MPa}: \sigma_{\text {com } .10}=6.0 \mathrm{MPa}$

Table 1. Test results of rocks under uniaxial $\left(\sigma_{0}\right)$ and volumetric compression $\left(\sigma_{10}=10 \mathrm{MPa}\right)$

\begin{tabular}{|c|c|c|c|c|c|c|c|c|c|}
\hline \multirow[t]{2}{*}{ № } & \multirow[t]{2}{*}{$\begin{array}{l}\text { Sampling } \\
\text { location }\end{array}$} & \multirow[t]{2}{*}{$\begin{array}{l}\text { Name } \\
\text { of coal } \\
\text { rocks }\end{array}$} & \multirow{2}{*}{$\begin{array}{c}\begin{array}{c}\text { Tensile } \\
\text { strength, } \\
\text { MPa }\end{array} \\
\sigma_{\text {ext.o }} \\
\end{array}$} & \multicolumn{2}{|c|}{$\begin{array}{c}\text { Compressive } \\
\text { strength, MPa. }\end{array}$} & \multicolumn{2}{|c|}{$\begin{array}{l}\text { Internal friction } \\
\text { angle, degree }\end{array}$} & \multicolumn{2}{|c|}{$\begin{array}{c}\text { Coefficient } \\
\text { of } \\
\text { adhesion, } \\
\text { MPa } \\
\end{array}$} \\
\hline & & & & $\sigma_{\text {com. } 0}$ & $\sigma_{\text {com.10 }}$ & $\varphi_{0}$ & $\varphi_{10}$ & $\mathbf{C}_{0}$ & $\mathbf{C}_{10}$ \\
\hline 1 & Formation 68 & Coal & & & & 6466 & & 0,9 & 2,9 \\
\hline 2 & $\begin{array}{c}\text { False roof of } \\
\text { the formation } \\
68\end{array}$ & $\begin{array}{l}\text { Carbona- } \\
\text { ceous }\end{array}$ & 1,6 & $10 \ldots 14$ & $15 \ldots 22$ & 57 & $36 \ldots 37$ & 10,2 & 181 \\
\hline 3 & $\begin{array}{l}\text { Basic roof of } \\
\text { the formation } \\
68\end{array}$ & Siltstone & 1,65 & $18 \ldots 29$ & $37 \ldots 49$ & $50 \ldots 53$ & $30 \ldots 34$ & 3,2 & 5,1 \\
\hline 4 & $\begin{array}{c}\text { Formation } \\
\text { soil } 68 \\
\end{array}$ & iltstone & 1,65 & $14 \ldots 23$ & $24 \ldots 41$ & $56 \ldots 58$ & $36 \ldots 37$ & 2,7 & 2,9 \\
\hline
\end{tabular}


The analysis of Table 1 shows that the mechanical characteristics of rocks differ significantly. The presence of a lateral spacer (depth simulation) increases the compressive resistance of the samples by $1.5 \ldots 1.8$ times with a decrease in the angle of internal friction and an increase in the coefficient of adhesion.

In $[14,15]$, the disadvantages of the volumetric compression chamber are described, including the inability to perform tests of rocks for rupture under volumetric compression. It is described as well as tests for rupture in the presence of lateral pressure (imitation of the depth of mineral occurrence), which is unknown in world practice, mainly due to the small diameter of the tested samples.

In the improved device, the diameters of the placed samples allow them to be installed in a bucket assembly with special devices $[14,15]$.

\section{Materials and methods}

In this regard, this paper describes in more details the device of the volumetric compression chamber and the ways of improving it by creating additional devices. Figure 2 shows a general view of the volumetric compression chamber (original design).

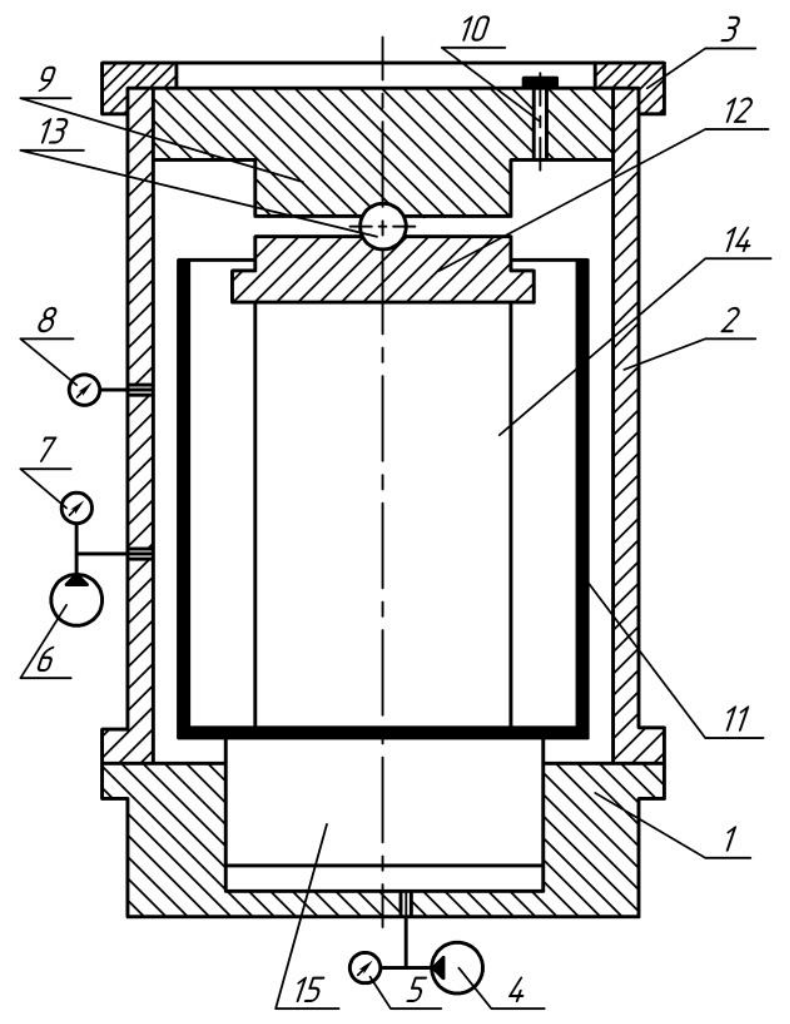

Fig. 2. General view of the camera "Azimuth" 85D01

According to Fig.2 the chamber consists of the upper and lower parts, where 1 - the lower cylinder (inner diameter $146 \mathrm{~mm}$ ), 2-the upper cylinder of the same diameter, 3-a removable ring for fixing the cover 9 of the upper cylinder. 4-the pump A-250 for loading the sample along the axis until the sample is destroyed, 5-a pressure gauge for measuring the pressure developed by the pump A-250 when feeding into the lower cylinder, 6-the pump BN-10 for supplying lateral pressure and maintaining its set pressure with a thickness 
of $\pm 5 \%$ ( $\mathrm{P} \max =25 \mathrm{kN}) .7$ - the pressure gauge of the pump BN 10,8 - pressure gauge for monitoring the lateral oil pressure (constant load during the test is provided by continuous manual control), 9-lid of the upper chamber with a hole for air release, 10-plug for opening the hole and releasing air from the upper chamber, 11-bucket for installing the test sample and storing rock residues after the destruction of the image (bucket diameter $137 \mathrm{~mm}$, height $260 \mathrm{~mm}$ based on the maximum possibility of placing samples $100 \times 200 \mathrm{~mm}$ ), 12plate mounted on the sample, 13-ball joint $\mathrm{d}=40 \mathrm{~mm}$ for uniform load transfer to the plate 9,14 - rock sample $(\mathrm{d}=50 \ldots 100 \mathrm{~mm} . \mathrm{H}=100-200 \mathrm{~mm}), 15$ - piston pusher for loading the sample 14 along the axis until destruction.

In order to improve the testing of samples for rupture, devices $[14,15]$ were created to secure the sample for descent into the bucket 11, but the first device [14] found the following disadvantages:

1) the load-bearing supports have a large weight, which made it difficult to install the assembled device with the sample in the bucket 11 ;

2 ) it is necessary to spend time moving the piston of the working cylinder of the volumetric compression chamber immediately before the tests in order to compensate for the changing parameters of the samples in the next batch.

These shortcomings were eliminated in the device [15], with the replacement of the ball indenter with a wedge one, and other shortcomings. The manufactured device is shown in Figure 3.

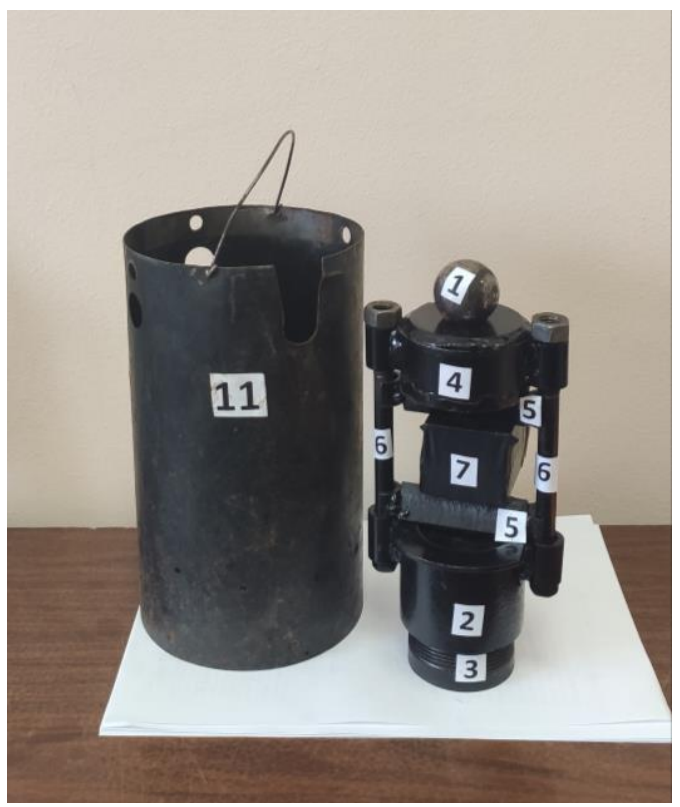

Fig. 3. Device for securing the sample before lowering it into the bucket 11

In Fig. 3 the positions for 11-bucket are marked (the position is saved from Fig. 2). It is for lowering the device with a fixed sample 1-ball joint; 2-lower retaining support; 3threaded retaining device that allows you to maintain a constant height for different samples of the next batch; 4-upper retaining support; 5-wedge indentors; 6-guide rods: 7-test sample covered with a protective film.

After placing the holding device with the sample in the bucket, it is lowered into the volumetric compression chamber. The sample is tested for rupture in the working chamber. 
The first experiments of the study of the tensile strength of rocks in the chamber of volumetric compression follow. The results are of testing the rocks of Taldinskaya Zapadnaya mine under volumetric compression $(\sigma \mathrm{cj} .10=10 \mathrm{MPa})$, Table 2 .

Table 2. Changes in the tensile strength of rocks under volumetric compression

\begin{tabular}{|c|c|c|c|c|c|c|}
\hline \multirow[t]{2}{*}{ № } & \multirow[t]{2}{*}{ Sampling location } & \multirow{2}{*}{$\begin{array}{l}\text { Name of coal } \\
\text { rocks }\end{array}$} & \multicolumn{2}{|c|}{$\begin{array}{l}\text { Compressive } \\
\text { strength }\end{array}$} & \multicolumn{2}{|c|}{$\begin{array}{l}\text { Ultimate tensile } \\
\text { strength, } \mathrm{MPa}\end{array}$} \\
\hline & & & $\sigma_{\text {com. } 0}$ & $\sigma_{\text {com } \cdot 10}$ & $\sigma_{\text {ext.0 }}$ & $\sigma$ ext.10 \\
\hline 1 & Formation 68 & Coal & $3,4 \ldots 5$ & $6.0 \ldots 11,5$ & $1,4 \ldots 3$ & $2,9 \ldots 4$ \\
\hline 2 & $\begin{array}{l}\text { The false roof of the } \\
\text { formation } 68\end{array}$ & $\begin{array}{c}\text { Carbonaceous } \\
\text { mudstone }\end{array}$ & $10 \ldots 14$ & $15 \ldots 22$ & $1 \ldots 4$ & $3 \ldots 6$ \\
\hline 3 & $\begin{array}{l}\text { The basic roof of the } \\
\text { formation } 68\end{array}$ & Siltstone & $18 \ldots .29$ & $37 \ldots 49$ & $1.5-5.1$ & $3,5 \ldots 12$ \\
\hline 4 & Formation soil 68 & Siltstone & $14 \ldots 23$ & $24 \ldots 41$ & $2 \ldots 6$ & $4 \ldots 15$ \\
\hline
\end{tabular}

Table 2 shows the strength characteristics when testing rocks for tension under volumetric compression increase by $1.5 . .2 .5$ times, compared to tests without simulating the depth of the rocks.

Figure 4 shows the passport of the volumetric strength of coal according to Table 1, when superimposed on this passport with dashed lines of the tensile strength of coal according to Table 2 .

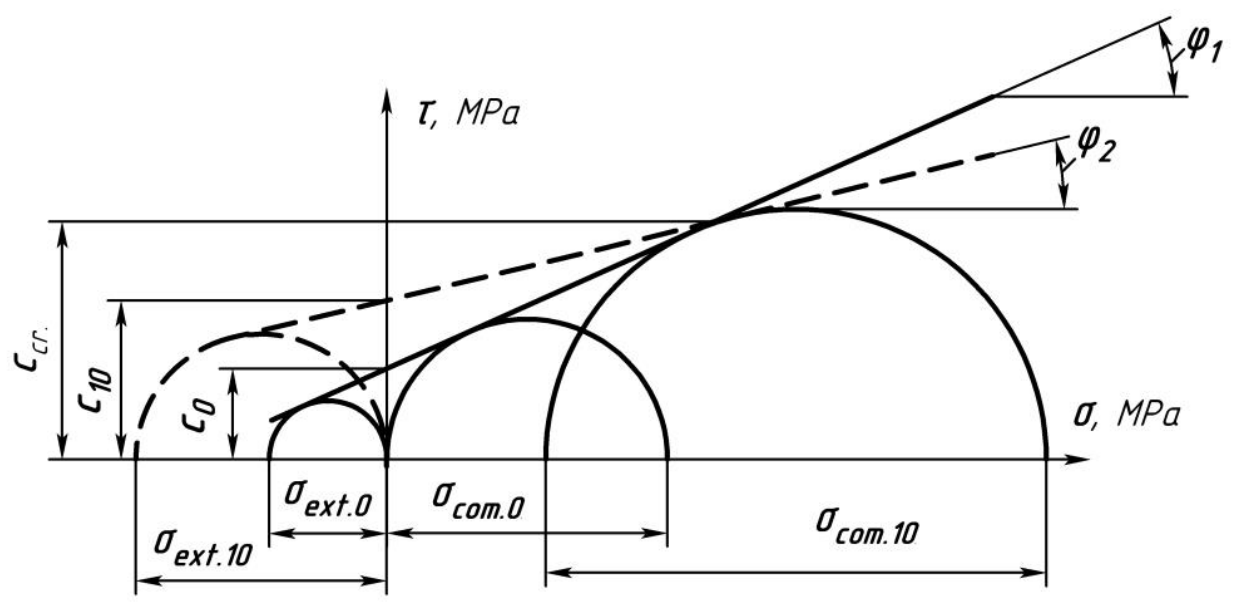

Fig. 4. Passport of the bulk strength of coal according to Table 1, with a dashed overlay coal tensile strength lines, getting a new strength passport. $\sigma_{\text {com. } .}=3.4 \mathrm{MPa} \sigma_{\text {com. } 10}=6.0 \mathrm{MPa} ; \sigma_{\text {ext. }}=1.4 \mathrm{MPa} \sigma_{\text {ext. } 10}=2.9 \mathrm{MPa}$, while the internal friction angle $\varphi_{1}=26$ decreased to $\varphi_{2}=14$

\section{Discussion of the results}

In demonstrating a simple graphical interpretation of the presence of important indicators of adhesion $\mathrm{C}$ and the angle of internal friction $\varphi$, the depth of the rocks is taking into account. It is shown that if the strength passport of coal with uniaxial compression $\sigma$ com. $=3.4 \mathrm{MPa}$ is applied to the strength limit at volumetric compression $\sigma$ com. $=6 \mathrm{MPa}$, the value of adhesion will increase from $\mathrm{C}=0.9 \mathrm{MPa}$ to $\mathrm{C}_{\mathrm{cr}}=2.9 \mathrm{MPa}$ (see Fig.1). Fig. 4 shows that the values of adhesion, taking into account the tensile strength at volumetric compression, increased from $\mathrm{C}_{0}=0.9 \mathrm{MPa}$, to $\mathrm{C}_{10}=2 \mathrm{MPa}$, and the internal friction angle $\varphi_{1}=26$, 
decreased to $\varphi_{2}=14$. Based on these comparisons, it can be concluded that the introduction of the passport of the rock tensile strength under volumetric compression increases the growth of the values of adhesion significantly. It also reduces the value of the internal friction angles. These values are of great importance in determining the bearing capacity of the host rocks around the preparatory workings. Thus, it is possible to build new passports of the volume strength of rocks and to obtain the characteristics of rocks for different depths of occurrence at the planned mining operations.

\section{Conclusion}

The work mentioned the diagrams of complete deformation of samples on the chamber of extreme deformation in combination with the changing passport of volumetric strength on the chamber of volumetric compression when using the last described device for fixing and testing large-sized samples [15]. They allow solving the tasks of implementing more indepth modern tests of rock samples in the laboratory of the KuzSTU (a branch in Prokopyevsk).

In the world practice, the tests for breaking with simulated rock occurrence have not been described yet. It is obviously, because in the volumetric compression chambers significantly smaller samples are traditionally tested.

\section{References}

1. V. Sotskov, O. Gusev, Progressive technologies of coal, coal bed methane, and ores mining (CRC Press, Balkema, 2014)

2. A. Renev, S. Kostyuk, N. Bedarev, Geomechanics Assignment Guides (Prokopyevsk, 2009)

3. V. Zubov, Journ. of Min. Inst., 225, 292 (2017)

4. J. Aggson, Coal Mine Floor Heave in the Beckley Coalbed (University of Michigan Library, 1978)

5. K. D. Erer, A. Heidarieh-Zadeh, Min. Sc. and Techn., 2, 3 (1985)

6. P. H. Lane, Rept. Invest. Bur. Mines us Dep. Intez, 89, 29 (1985)

7. T. Barczak, S. Tadolini, SME Ann. Meet., 253, 16 (Pittsburg, 2005)

8. L. Fu-chen, Zh. Wei, S. Ai-hua, The El. J. of Geotech. Eng., 18, 1221 (2013)

9. P. Peng-Zhi, J. Rutqvist, F. Xia-Ting, Y. Fei, J. Quan, Rock Mech. and Rock Eng., 47, $6(2014)$

10. J. L. Luo, Gateroad design in overlying multi-seam mines (West Virginia University, Parkersberg, 1997)

11. C. Mark, Multiple-seam longwall mining in the United States: lessons for ground control (NIOSH, Pittsburgh, 2007)

12. S. Kostyuk, G. Sitnikov, N. Bedarev, N. Kovalev, O. Lyubimov, Field dev., 275 (2013)

13. S. Kostyuk, N. Bedarev, O. Lyubimov, E3S Web of Conf. 174, 01007 (2020)

14. Pat. 184648 of Russian Federation (2018)

15. Pat. 193857 of Russian Federation (2019) 